\title{
Avaliação da Conservação de Nascentes no Assentamento Caricé no Estado de Pernambuco
}

\section{Evaluation of the Conservation of Springs in the Caricé Settlement in the State of Pernambuco}

Lívia Câmara Machado ${ }^{a}$

Ricardo Augusto Pessôa Braga ${ }^{b}$

\author{
a Universidade Federal de Pernambuco. Doutora em Desenvolvimento e \\ Meio Ambiente pela Universidade Federal de Pernambuco - UFPE. \\ E-mail: liviamachado.biologa@gmail.com
}

ORCID iD: http://orcid.org/0000-0002-3662-1437

\footnotetext{
b Universidade Federal de Pernambuco. Doutor em Engenharia Civil pela Universidade de São Paulo - USP e Professor Adjunto da Universidade Federal de Pernambuco - UFPE.

E-mail: rbraga@hotlink.com.br
}

\section{RESUMO}

As nascentes são fontes essenciais de água e capazes de suprir as demandas nos espaços rurais. A importância do seu estudo nestes espaços torna-se essencial, na intenção de compreender o seu uso e valor nas diversas atividades realizadas pelos agricultores familiares em prol da sustentabilidade hídrica. Em decorrência dos problemas vivenciados pelos usos e apropriações inadequadas de áreas de nascentes, impactos negativos são visíveis e dificultam a conservação destas fontes que são importantes formas de acesso à água no meio rural. $\mathrm{O}$ artigo pretende avaliar o estado de conservação das nascentes na sustentabilidade hídrica de assentamentos rurais. As técnicas adotadas no estudo foram realizadas através da pesquisa de campo e de laboratório, utilizando parâmetros para a avaliação do 
estado de conservação de nascentes no corpo e no entorno das nascentes. A área de estudo encontra-se inserida na mesorregião da Mata Pernambucana e corresponde ao Assentamento Caricé no município de Vitória de Santo Antão. A avaliação atual das nascentes aponta que a maioria dessas fontes apresenta situação regular de conservação, o que evidencia a necessidade de medidas de proteção destes mananciais, que são enquadrados na legislação como áreas de preservação permanente e, no entanto, sofrem impactos diretos. Sugere-se o desenvolvimento de ações de educação ambiental, na tentativa de estimular a reflexão destes atores sobre os impactos negativos observados nas áreas das nascentes estudadas, principalmente na importância de se conservar esses mananciais para que consequentemente eles não sejam degradados.

Palavras-chave: Conservação. Nascentes. Avaliação.

\section{ABSTRACT}

The springs are essential sources of water and able to meet the demands of rural areas. The importance of their study in these spaces becomes essential in order to understand their use and value in the various activities carried out by family farmers in support of water sustainability. Due to the problems experienced by inappropriate uses and appropriations of spring areas, negative impacts are visible and make it difficult to conserve these sources, which are important forms of access to water in rural areas. The article intends to evaluate the state of conservation of the springs in the water sustainability of rural settlements. The techniques adopted in the study were carried out through field and laboratory research, using parameters to evaluate the state of conservation of springs in the body and in the surroundings of the springs. The study area is located in the mesoregion of Mata Pernambucana and corresponds to the Caricé settlement in the city of Vitória de Santo Antão. The current assessment of the sources indicates that most of these sources present a regular conservation situation, which evidences the need for measures to protect these springs, which are framed in the legislation as permanent preservation areas and yet suffer direct impacts. It is suggested the development of environmental education actions in an attempt to stimulate the reflection of these actors on the negative impacts observed in the areas of the sources studied, especially on the importance of conserving these sources so that they are not degraded.

Keywords: Conservation. Springs. Evaluation. 


\section{INTRODUÇÃO}

As primeiras intervenções utilizando á água foram realizadas na Idade Média, exemplificadas por sua diferente apropriação na criação de moinhos - com a finalidade de gerar força motriz (MACHADO, 2013). Evidencia-se que a partir deste marco ocorreu uma mudança de concepção da importância da água, antes vista como um elemento necessário à manutenção e reprodução da vida, que após esta fase, passou a ser um novo recurso apropriado para os fins de produção de trabalho no atendimento às necessidades sociais (REBOUÇAS, 2006).

Dado o contexto do paradigma capitalista, a relação sociedade-natureza após a Revolução Industrial passa a ser concebida de forma diferente, sendo visualizada nas diferentes maneiras de apropriação dada pelo homem à água. Acrescenta Rebouças (2006) que a água é essencial ao abastecimento do consumo humano e ao desenvolvimento de suas atividades industriais e agrícolas e é de importância vital aos ecossistemas - tanto vegetal como animal - das terras emersas.

Dada à relação sociedade-natureza, grandes conflitos podem ser percebidos nos desiguais acessos à água e no descaso ambiental, decorrentes dos usos inadequados e das atividades que até os dias atuais impulsionam a indústria e o avanço tecnológico. Para Christofidis (2002) a disponibilidade de água deve atender às necessidades básicas dos seres humanos primordialmente, mas deve também ocorrer em conjunto com o atendimento às necessidades ambientais.

Em decorrência dos problemas vivenciados pelos usos e apropriações inadequadas de áreas de nascentes, impactos negativos são visíveis e dificultam a conservação destas fontes que são importantes formas de acesso à água no meio rural. No contexto dos espaços rurais, Braga (2011) indica as nascentes como única fonte que, na maioria das vezes atende às demandas nos espaços rurais e que por sua vez possuem grande importância no desenvolvimento das atividades realizadas nos assentamentos que geram a subsistência destes atores sociais.

Segundo Machado e Selva (2018) as nascentes são importantes fontes de água para sobrevivência das famílias rurais utilizadas tanto nas atividades domésticas quanto agrícolas. São importantes fontes de água que suprem as 
necessidades no meio rural, principalmente pela ausência de um serviço público de abastecimento.

As nascentes são recursos essenciais para os assentamentos humanos e espécies terrestres, além de habitats para a biota aquática que contribuem para os processos ecológicos e biodiversidade (DAVIS et al., 2016). O Código Florestal Brasileiro, no Art. $3^{\circ}$, prevê a conservação destas áreas que facilitam o fluxo gênico de fauna e flora, protegem o solo e são capazes de assegurar o bem-estar das populações humanas (BRASIL, 2012).

Enquadradas como Áreas de Preservação Permanente - APPs, a Resolução do Conselho Nacional de Meio Ambiente (CONAMA) $n^{\circ} 303$, de 20 de março de 2002, em seu Art. $3^{\circ}$, inciso II, expressa que as Áreas de Preservação Permanente são áreas protegidas, cobertas ou não por vegetação nativa e que a ela incumbe-se a função ambiental de preservar os recursos hídricos, a paisagem, a estabilidade geológica e a biodiversidade (CONAMA, 2002). Na mesma Resolução o termo "nascente" é considerado como o local onde aflora naturalmente, mesmo que de forma intermitente a água subterrânea.

Felippe e Magalhães Junior (2013) conceituam as nascentes como um sistema ambiental em que o afloramento da água subterrânea ocorre naturalmente, de modo temporário ou perene, e cujos fluxos hidrológicos na fase superficial são integrados à rede de drenagem.

As nascentes também são pontos iniciais dos cursos d'água, formadores dos pequenos e grandes rios (PINTO, 2003). A característica de uma nascente é essencialmente a de manter um córrego, que por sua vez também estará contribuindo para outro curso maior - a essa contribuição vincula-se o volume de água que alimenta os cursos e são capazes de formar o principal rio de uma bacia hidrográfica. O que significa que a redução do número de nascentes interfere diretamente no número de cursos de água, ou seja, na disponibilidade hídrica de determinado local.

Sendo assim, a importância do estudo das nascentes nestes espaços tornase essencial na intenção de compreender o seu uso e valor nas diversas atividades realizadas pelos agricultores familiares em prol da sustentabilidade hídrica em áreas de assentamentos rurais. Diante do exposto, torna-se fundamental identificar o estado de conservação das nascentes com o intuito de compreender as principais Ciência e Sustentabilidade - CeS / Juazeiro do Norte, v. 4, n. 1, p. 133-155, jan/jun - 2018 
atividades realizadas pelos assentados de reforma agrária, visando à manutenção do recurso e o planejamento adequado de ações de conservação em prol da sustentabilidade nestes espaços.

Destarte, o artigo pretende avaliar o estado de conservação das nascentes na sustentabilidade hídrica do Assentamento Rural Caricé, localizado no município de Vitória de Santo Antão, no Estado de Pernambuco.

\section{MATERIAL E MÉTODOS}

\subsection{Procedimentos metodológicos}

As técnicas adotadas no estudo foram realizadas através da pesquisa de campo e de laboratório. A pesquisa de campo foi realizada por meio da observação in loco, com o apoio de entrevistas estruturadas com os assentados de reforma agrária. As nascentes identificadas foram georreferenciadas, utilizando o GPS 12 Personal Navigator ${ }^{\circledR}$ da marca GARMIN, seguido da realização de entrevistas com os assentados e posterior registro fotográfico. Na pesquisa de laboratório, as 16 amostras de água foram analisadas no Laboratório do Centro de Tecnologia e Geociências da Universidade Federal de Pernambuco a fim de verificar os parâmetros relacionados à qualidade da água na metodologia utilizada.

Neste estudo, para analisar as nascentes adotou-se os parâmetros de avaliação do estado de conservação de nascentes, seguindo a proposta das autoras Pereira (2012), Machado (2013) e Oliveira (2014) e validada especificamente para análise de nascentes em assentamentos rurais. A proposta incorpora 12 parâmetros de análise, distribuídos em 02 critérios de localização, no entorno e no corpo das nascentes (PEREIRA, 21012; MACHADO, 2013; OLIVEIRA, 2014). Na metodologia, as nascentes são enquadradas em bom, regular e ruim estado de conservação mediante uma escala de pontuação pré-estabelecida.

Para a avaliação do estado de conservação das nascentes utilizou-se uma amostra escolhida a partir de critérios identificados nesta pesquisa, que optou pelas nascentes que são utilizadas especialmente para o consumo humano, agrupadas como uso pessoal e uso doméstico. Ressalta-se a abordagem específica dos usos

Ciência e Sustentabilidade - CeS / Juazeiro do Norte, v. 4, n. 1, p. 133-155, jan/jun - 2018 
direcionados ao consumo humano. No uso pessoal - na dessedentação humana, na preparação de alimentos e na higiene corporal. No uso doméstico - na limpeza dos utensílios da casa, na lavagem de roupas e na limpeza da casa.

A amostra das nascentes para atendimento do objetivo deste trabalho compreende as parcelas 01 (N1), 05 (N1 e N2), 08 (N1 e N2), 09 (N1), 10 (N1), 12 (N1 e N2), 13 (N4), 15 (N2 e N3), 18 (N1), 19 (N1), 21 (N1) e 23 (N1), totalizando 16 nascentes analisadas através de uma única coleta. A metodologia para a identificação do estado de conservação das nascentes foi aplicada no período de estiagem, em janeiro de 2013, considerando ainda o período de resiliência das nascentes no intuito de observar a suas condições no período mais crítico do ano.

\section{2 Área de Estudo}

O Estado de Pernambuco possui cinco mesorregiões geográficas: as mesorregiões Sertão, do São Francisco, do Agreste, da Mata e Metropolitana do Recife. A área de estudo encontra-se inserida na mesorregião da Mata Pernambucana (Figura 1), que possui sua área total de $8.827,6 \mathrm{~km}^{2}$, ocupa aproximadamente $9,0 \%$ do território do Estado compreendendo 43 municípios e 03 microrregiões (PERNAMBUCO, 2006).

O Assentamento Caricé está inserido na bacia hidrográfica do rio Capibaribe (UP-2), na sub-bacia do rio Tapacurá, no município de Vitória de Santa Antão, porção norte-oriental do Estado de Pernambuco (PERNAMBUCO, 2006). município possui o clima tropical chuvoso com verão seco, de precipitação média anual de 1309,9 mm; a vegetação predominante é do tipo Floresta Subperenifólia com partes de Floresta Hipoxerófila.

Segundo o Plano de Desenvolvimento do Assentamento Caricé, o imóvel situa-se entre os meridianos de $35^{\circ} 10^{\prime}$ e $35^{\circ} 30^{\prime}$ de longitude Oeste de Greenwich e os paralelos de $7^{\circ} 50^{\prime}$ e $8^{\circ} 15^{\prime}$ de latitude sul, inserido na porção centro-oeste da Mesorregião da Mata Pernambucana (INCRA, 2002). A região está inserida na paisagem denominada "Mar de Morros", com a predominância de solos do tipo latossolos e podzólicos (CPRM, 2005). 
A rede hidrográfica da região é formada por pequenos rios e riachos que compõem parte da Bacia Hidrográfica. A área de estudo é cortada pelo Riacho do Meio, de curso permanente, porém, insignificante para a irrigação devido à quantidade de água disponível. Considera-se a poluição das águas como principal fator de limitação do assentamento uma vez que interfere completamente no seu uso prioritário, o consumo humano (INCRA, 2002).

A princípio, o assentamento foi criado com a capacidade para 18 famílias, porém atualmente conta com 19 famílias assentadas que totalizam 89 pessoas distribuídas nas 15 parcelas. A organização social da comunidade é orientada pela Associação dos Trabalhadores Rurais do Assentamento Caricé e pelo Sindicato dos Trabalhadores Rurais do Município de Vitória de Santo Antão. Considerando as 19 famílias assentadas, a maioria não obtém renda familiar significante e sobrevive exclusivamente da mão-de-obra do campo em seus cultivos temporários e na pecuária para a subsistência, restando à minoria as atividades realizadas no centro do município (MACHADO, 2013).

\section{RESULTADOS E DISCUSSÃO}

O assentamento conta com 40 nascentes fluviais distribuídas em 15 parcelas do Assentamento Rural Caricé, sendo uma única disponível na área comunitária (MACHADO, 2013). Com relação ao posicionamento das nascentes, Machado e Soares (2018) observou a ocorrência e sua distribuição no assentamento com predominância de fontes na porção norte. Nota-se ainda uma incidência maior de nascentes nas proximidades da área de Reserva Legal do assentamento.

De acordo com o georreferenciamento, este quantitativo equivale a $78,9 \%$ das parcelas do assentamento, restando apenas $21,1 \%$ para as parcelas que não possuem nascentes (Figura 2). Outro aspecto observado é a incidência de nascentes de depressão, localizadas em áreas de baixio. 
Figura 2- Mapeamento das nascentes do Assentamento Caricé em Vitória de Santo Antão (PE).

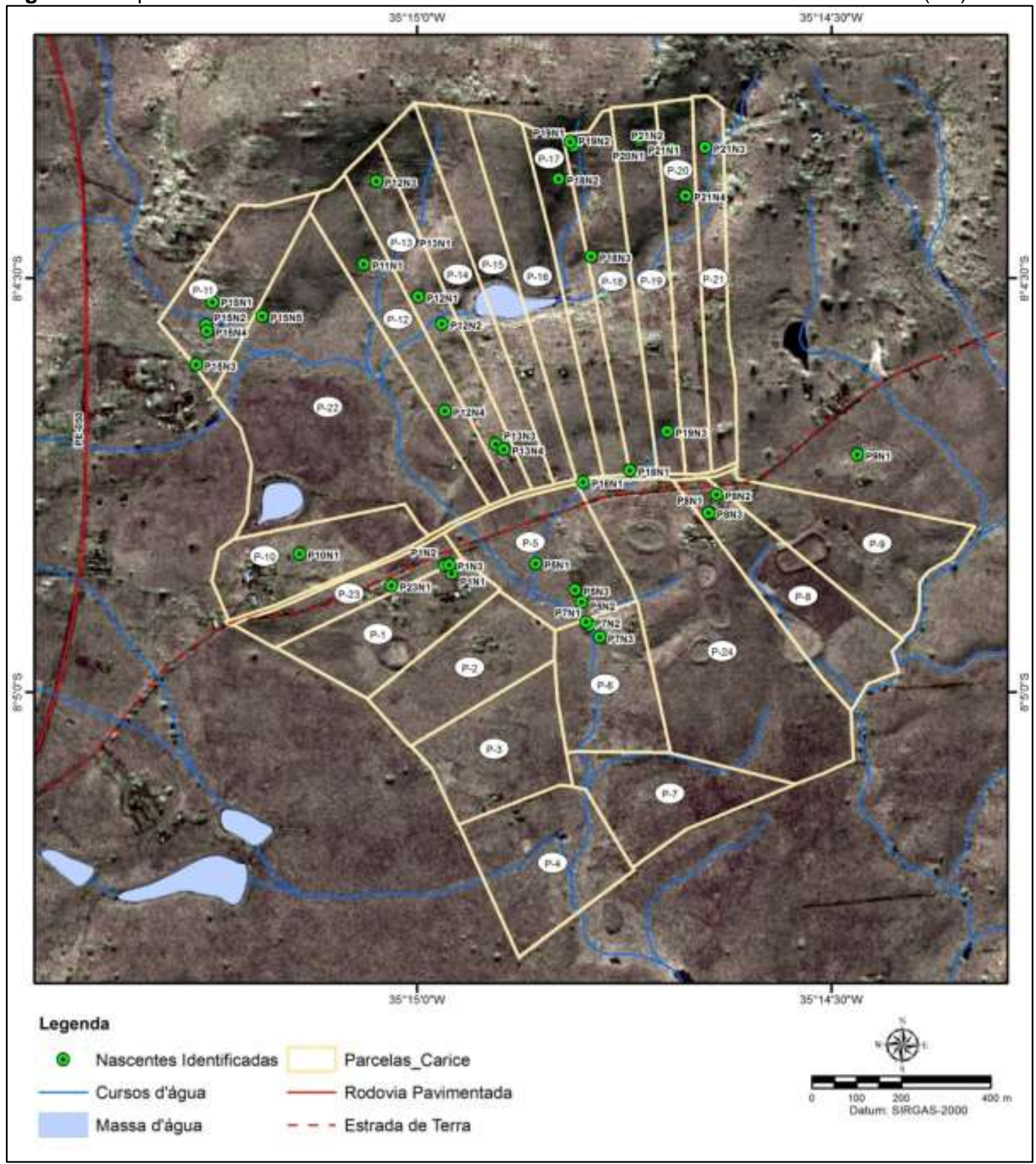

Fonte: CPRM (2014); INCRA (2002).

Os resultados da análise de turbidez nas nascentes de uso pessoal, durante o mês de janeiro de 2013 apontam 03 nascentes dentro do limite estabelecido na Portaria MS 2914/2011, com os valores inferiores a 5 UT (Figura 3). Ressalta-se que para fins do consumo humano, estas nascentes devem passar por um tratamento de Ciência e Sustentabilidade - CeS / Juazeiro do Norte, v. 4, n. 1, p. 133-155, jan/jun - 2018 
desinfecção para se enquadrarem dentro dos padrões da Classe Especial (MS, 2011).

Figura 3 - Turbidez da água das nascentes de uso pessoal no período seco no Assentamento Caricé, Vitória de Santo Antão (PE).

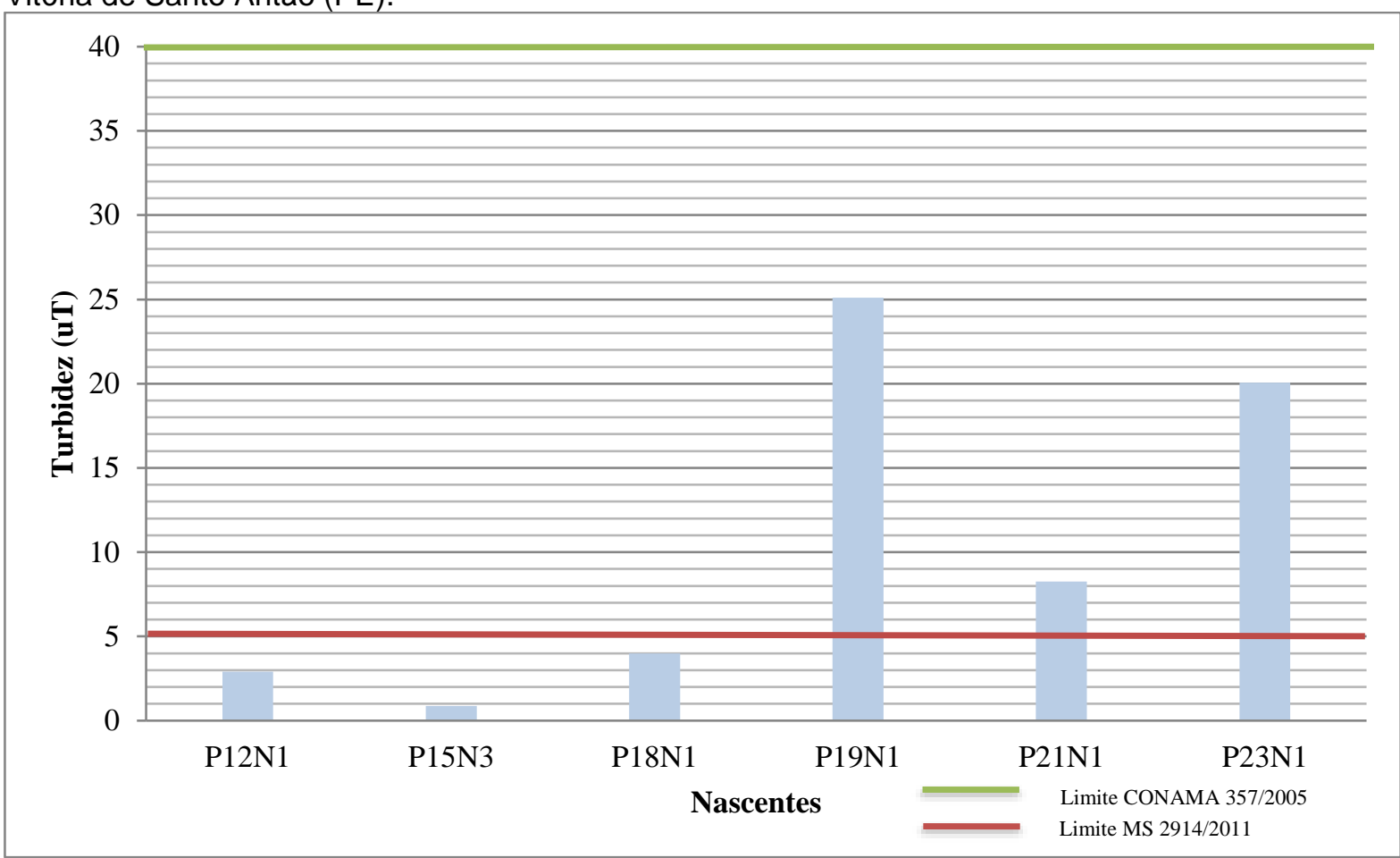

Fonte: Dados da Pesquisa de campo, em janeiro de 2013.

Outras 03 nascentes utilizadas na dessedentação humana e uso pessoal estão em desconformidade com a referida Portaria. Porém, essas fontes se encontram dentro dos limites estabelecidos pela Resolução CONAMA 357/05, na Classe 1, com até 40 uT (CONAMA, 2005). Os valores atendem o exigido para o abastecimento doméstico, a proteção de comunidades aquáticas e recreação de contato primário, desde que submetidas ao tratamento convencional.

Pinto et al. (2012) encontraram valores altos para o parâmetro de turbidez nas cinco nascentes no Município de Inconfidentes - MG, situadas no Bairro dos Romas, localizado na bacia hidrográfica do rio Mogi Guaçu. No estudo, os autores apontaram que a presença de pastagem foi relacionada com o valor de $52 \mathrm{uT}$, indicando o indevido uso da pastagem nas áreas de nascentes, dada pela presença dos animais de criação que bebem a água.

Neste estudo, a elevação da turbidez pode estar associada à vegetação predominante no entorno das nascentes. As nascentes P19N1 e P21N1 possuem no seu entorno o cultivo da cana-de-açúcar, recentemente queimados por um incêndio.

Ciência e Sustentabilidade - CeS / Juazeiro do Norte, v. 4, n. 1, p. 133-155, jan/jun - 2018 
Outro aspecto observado é o transporte da água de algumas nascentes que é realizado via tubulações, chegando até a residência dos agricultores por gravidade. Convém ressaltar que as duas nascentes possuem suas estruturas de proteção completas e em perfeito estado. Já P23N1 evidenciou dados de turbidez insatisfatórios em decorrência da sua estrutura de proteção incompleta, que facilita a entrada de sedimentos no corpo da nascente.

As nascentes de usos domésticos apresentaram uma realidade diferente das nascentes de uso pessoal, apenas 02 estão dentro do limite estabelecido pela Portaria MS 2914/201, e 04 estão em conformidade (Figura 4). A nascente P08N2 apresenta a sua turbidez dentro da faixa das águas de Classes 2 e 3 com valores (s100uT) e, portanto, de acordo para o abastecimento doméstico desde que seja realizado o tratamento convencional.

Figura 4 - Turbidez da água das nascentes de uso doméstico no período seco no Assentamento Caricé, Vitória de Santo Antão (PE).

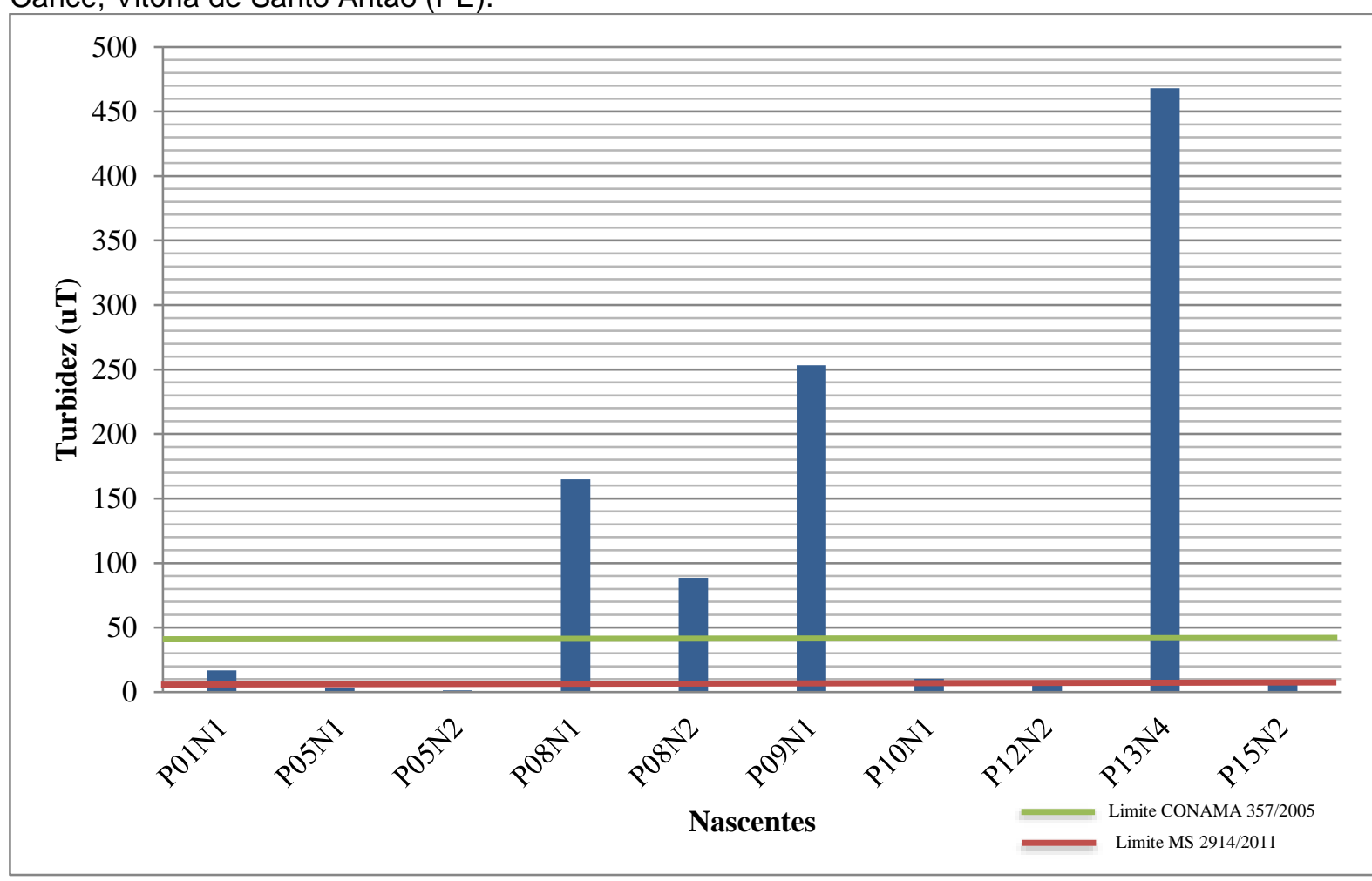

Fonte: Dados da Pesquisa de campo, em janeiro de 2013.

Observa-se que 03 nascentes apresentaram valores acima de 100uT e de acordo com os resultados da análise de turbidez, a água destas fontes se enquadram na Classe IV, destinadas à navegação e à harmonia paisagística. No entanto, são utilizadas pelos assentados nas atividades domésticas realizadas.

Ciência e Sustentabilidade - CeS / Juazeiro do Norte, v. 4, n. 1, p. 133-155, jan/jun - 2018 
Com relação à presença de E. coli, 04 nascentes analisadas apresentaram conformidade de acordo com a Portaria MS 2914/2011, apresentando valores $\leq 1$ $\mathrm{NMP} / 100 \mathrm{~mL}$. A presença de Escherichia coli foi detectada em 02 nascentes, a P23N1 e P18N1, que durante o período seco apresentaram o valor de 292,4 e 3 $\mathrm{NMP} / 100 \mathrm{~mL}$, respectivamente, estando em desconformidade com a Portaria MS 2914/11. Ressalta-se que esta primeira nascente também ultrapassa os limites estabelecidos pela Resolução CONAMA 274/2000 (CONAMA, 2000).

Desta forma, a segunda, a P18N1 encontra-se enquadrada nos padrões de balneabilidade, estando em condição excelente para banho. Observa-se que esta fonte é considerada a mais limpa pelos assentados, sendo utilizada na dessedentação humana. As demais nascentes estão em conformidade com a referida Portaria apresentando ausência de E.coli, portanto, estão adequadas para o consumo humano após desinfecção (Figura 5).

Figura 5 - Escherichia coli nas nascentes de uso pessoal no período seco no Assentamento Caricé, Vitória de Santo Antão (PE).

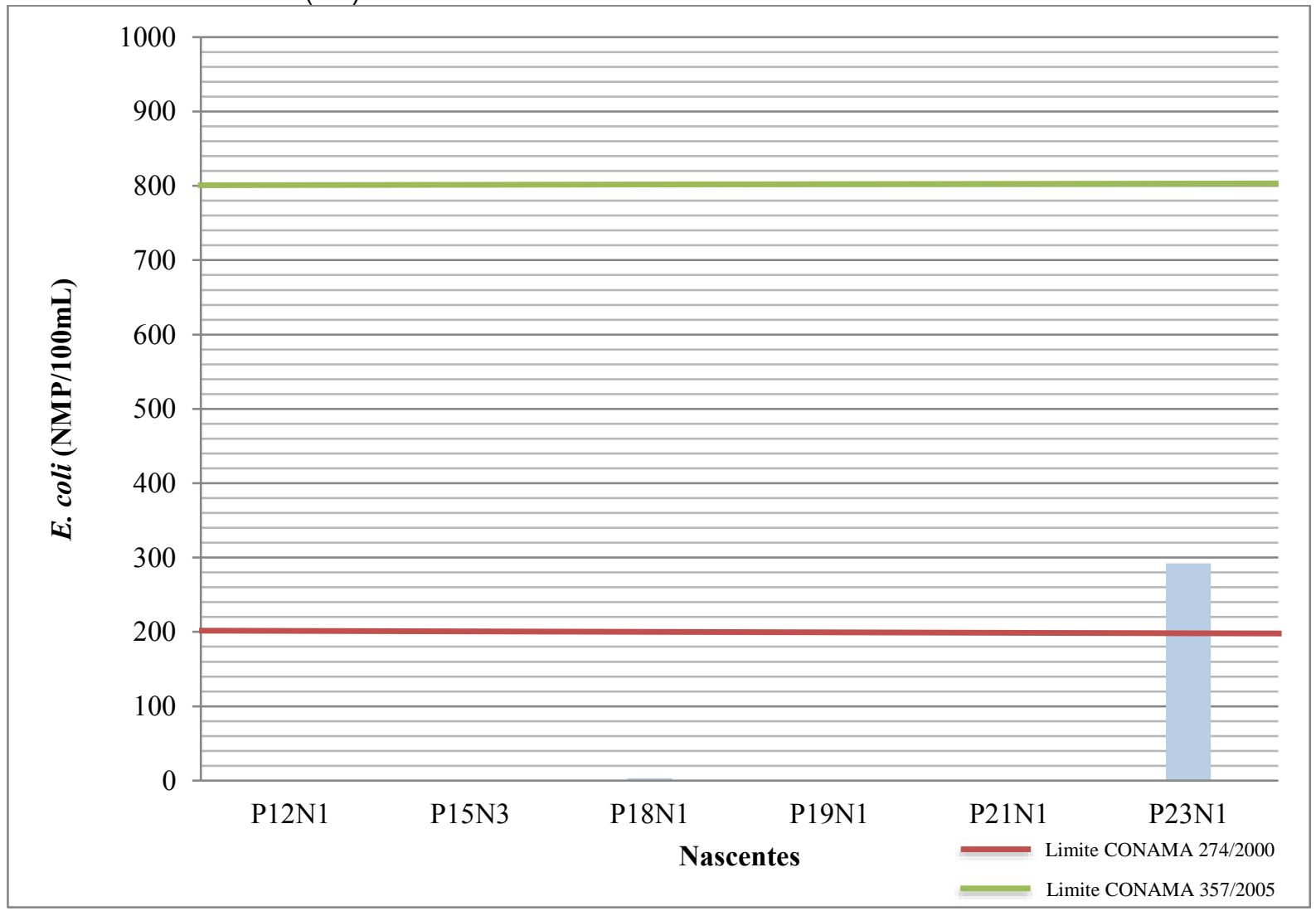

Fonte: Dados da Pesquisa de campo, em janeiro de 2013. 
Nas nascentes de uso doméstico, a P09N1 e a P13N4 apresentaram valores acima do limite estabelecido pela Resolução CONAMA 357/2005, com 1011,2 e 960,6 NMP/100 mL, respectivamente. Estão em desconformidade com a referida Resolução sendo consideradas águas com qualidade insatisfatória (Figura 6). As nascentes P08N1 e P10N1 que ultrapassaram o limite da Resolução CONAMA 274/2000, com seus valores de 689,3 e 478,6 NMP/100 mL estão enquadradas como águas para recreação de contato primário segundo a Resolução CONAMA 357/2005 (CONAMA, 2005).

A P01N1, P05N1, P05N2, P08N2, P12N2, e P15N2 que apresentaram seus valores $\leq 200 \mathrm{NMP} / 100 \mathrm{~mL}$ estão em conformidade com a Resolução CONAMA 274/2000 como águas excelentes para banho (CONAMA, 2000). Da amostra das nascentes de uso doméstico, apenas a P12N2 apresentou o valor $\leq 1$, estando em conformidade de acordo com a Portaria MS 2914/2011(MS, 2011).

Figura 6 - Escherichia coli nas nascentes de uso doméstico no período seco no Assentamento Caricé, Vitória de Santo Antão (PE).

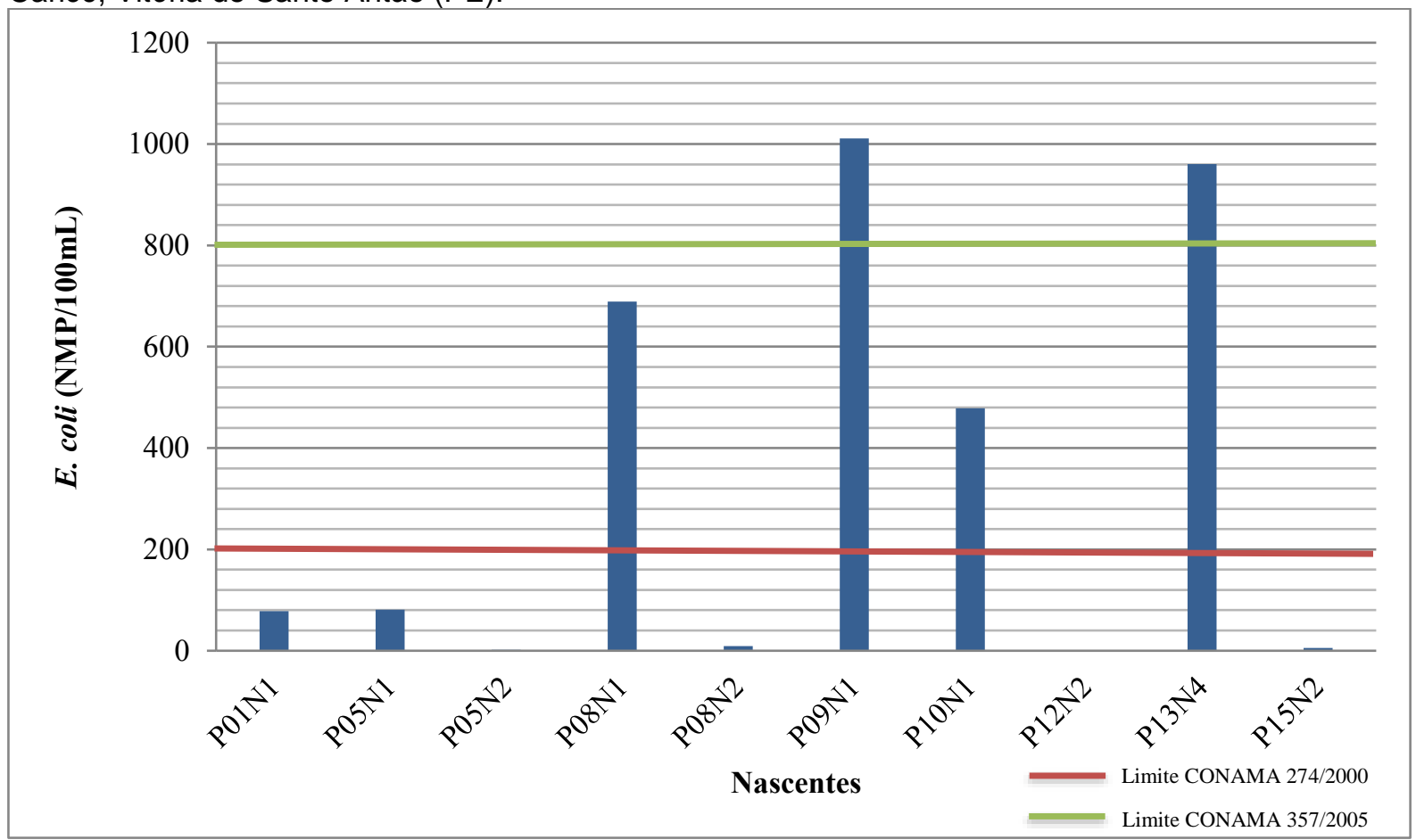

Fonte: Dados da Pesquisa de campo, em janeiro de 2013.

Com relação à presença de coliformes fecais, o critério analisado pôde enquadrar as nascentes com a pontuação mínima, que são: P08N1, P09N1, P10N1 e P13N4, cujo seus valores atingiram o intervalo de $>400 \leq 800$ (NMP/100 mL). Desta forma, uma nascente obteve o seu valor na faixa $>200 \leq 400$ e sete nascentes nos Ciência e Sustentabilidade - CeS / Juazeiro do Norte, v. 4, n. 1, p. 133-155, jan/jun - 2018 
valores $\leq 200(\mathrm{NMP} / 100 \mathrm{~mL})$. Destaca-se a ocorrência de quatro nascentes que apresentaram a pontuação máxima estando dentro do limite estabelecido pela Portaria MS 2914/2011 (MS, 2011).

De acordo com a presença de resíduos sólidos observa-se que a P12N1 e a P10N1 apresentaram restos de vasilhames deteriorados, utilizados para a captação de água. Nas demais nascentes há a predominância de resíduos no seu entorno, porém, para atribuição da pontuação neste parâmetro foram considerados os resíduos encontrados dentro das fontes.

Cunha (2014) avaliou o estado de conservação de 09 nascentes na Reserva Biológica de Saltinho, no município de Tamandaré, em Pernambuco e encontrou que todas as nascentes de sua amostra apresentaram ausência de resíduos sólidos. Os valores se justificam devido área de estudo do autor enquadrar-se no Sistema Nacional de Unidades de Conservação (SNUC), sendo, portanto, uma área de preservação integral da biota e demais atributos naturais, gerida pelo ICMBio Instituto Chico Mendes de Conservação da Biodiversidade.

A presença de agrotóxico na água foi confirmada por um agricultor, da P05N2, que no seu entorno possui o cultivo da cana-de-açúcar e foi confirmado pelo mesmo o uso do Roundup - agrotóxico mais comum utilizado no assentamento. Ressalta-se que no momento da aplicação da entrevista realizada em agosto de 2012, foi registrado pela agricultora da parcela 09 o uso da água desta nascente, sendo posteriormente interrompido devido à ocorrência de diarreia nas crianças. Desta forma, apenas as nascentes P19N1 e P21N1apresentaram a ausência de suspeita devido à proteção física das fontes. As demais fontes estão apenas com a suspeita de presença de agrotóxico.

Outro aspecto observado foi o uso direto das nascentes, que apontaram as nascentes P05N1, P09N1, P12N2 e P13N4 com a menor pontuação. Neste caso os diversos usos estão sendo realizados diretamente nas nascentes. Neste aspecto, as demais fontes apresentaram o uso frequente, sendo a principal prática na nascente a utilização de baldes ou vasilhames para a captação da água.

Machado e Selva (2018) analisando o potencial de conservação das nascentes no Assentamento Rural Caricé avaliou o parâmetro "Uso da água", constatando valores baixos com relação à utilização diária da água da nascente. No estudo as autoras indicaram as nascentes (N09, N19, N21 e N23) como as fontes

Ciência e Sustentabilidade - CeS / Juazeiro do Norte, v. 4, n. 1, p. 133-155, jan/jun - 2018 
mais utilizadas e com possibilidade de comprometimento na disponibilidade hídrica da nascente.

Com relação a desproteção física, a P15N2 e P13N4 apresentaram ausência de estruturas de proteção, o que influência diretamente nas alterações da qualidade da água da nascente. Desta forma, 11 nascentes estão com ausência de cobertura da parte superior ou grave comprometimento da estrutura lateral e apenas 01 está com a sua estrutura incompleta (P23N1). Neste aspecto as nascentes P19N1 e P21N1 estão completas.

De acordo com as observações realizadas constata-se que para as nascentes de uso pessoal, apenas uma encontra-se com a classificação regular de conservação (P23N1). As demais nascentes foram enquadradas no intervalo de 12 a 18 (Figura 7) estão consideradas com um bom estado de conservação no corpo da nascente.

Figura 7 - Estado de conservação localizado no corpo das nascentes de uso pessoal no Assentamento Caricé, Vitória de Santo Antão (PE).

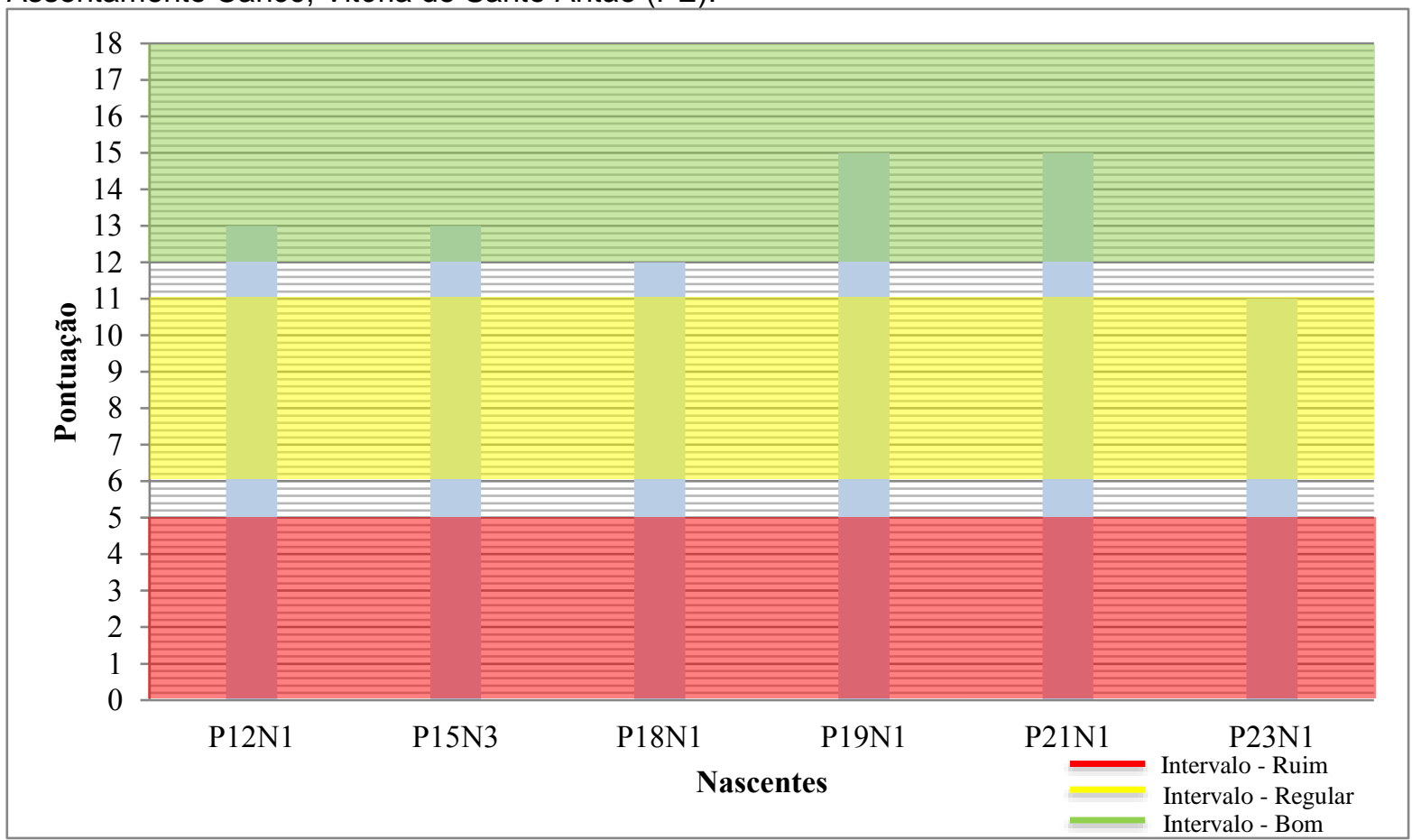

Fonte: Dados da Pesquisa de campo, em janeiro de 2013.

Cunha (2014) avaliou o estado de conservação das nascentes na Reserva Biológica de Saltinho, Tamandaré (PE) e constatou que todas as nascentes possuíam um bom estado de conservação, apontando a preservação nas áreas de nascentes inclusas no Sistema de Unidades de Conservação - SNUC. Ressalta-se

Ciência e Sustentabilidade - CeS / Juazeiro do Norte, v. 4, n. 1, p. 133-155, jan/jun - 2018 
que a Reserva Biológica de Saltinho é uma Unidade de Proteção Integral, sendo admitido apenas o uso indireto dos seus recursos naturais, o que justifica o resultado do autor.

Nas nascentes utilizadas para o abastecimento doméstico observa-se uma queda na pontuação que indica o seu estado de conservação. De acordo com as observações realizadas constata-se que 08 nascentes apresentam a classificação regular (Figura 8), e 02 foram enquadradas no intervalo de 0 a 5 , sendo consideradas com o estado de conservação ruim, na situação locacional no corpo da nascente.

Em suma, o levantamento demonstra que das 16 nascentes analisadas, 02 estão com ruim estado de conservação, 09 se apresentam em estado regular, restando 05 nascentes em boas condições de conservação.

Figura 8 - Estado de conservação localizado no corpo das nascentes de uso doméstico no Assentamento Caricé, Vitória de Santo Antão (PE).

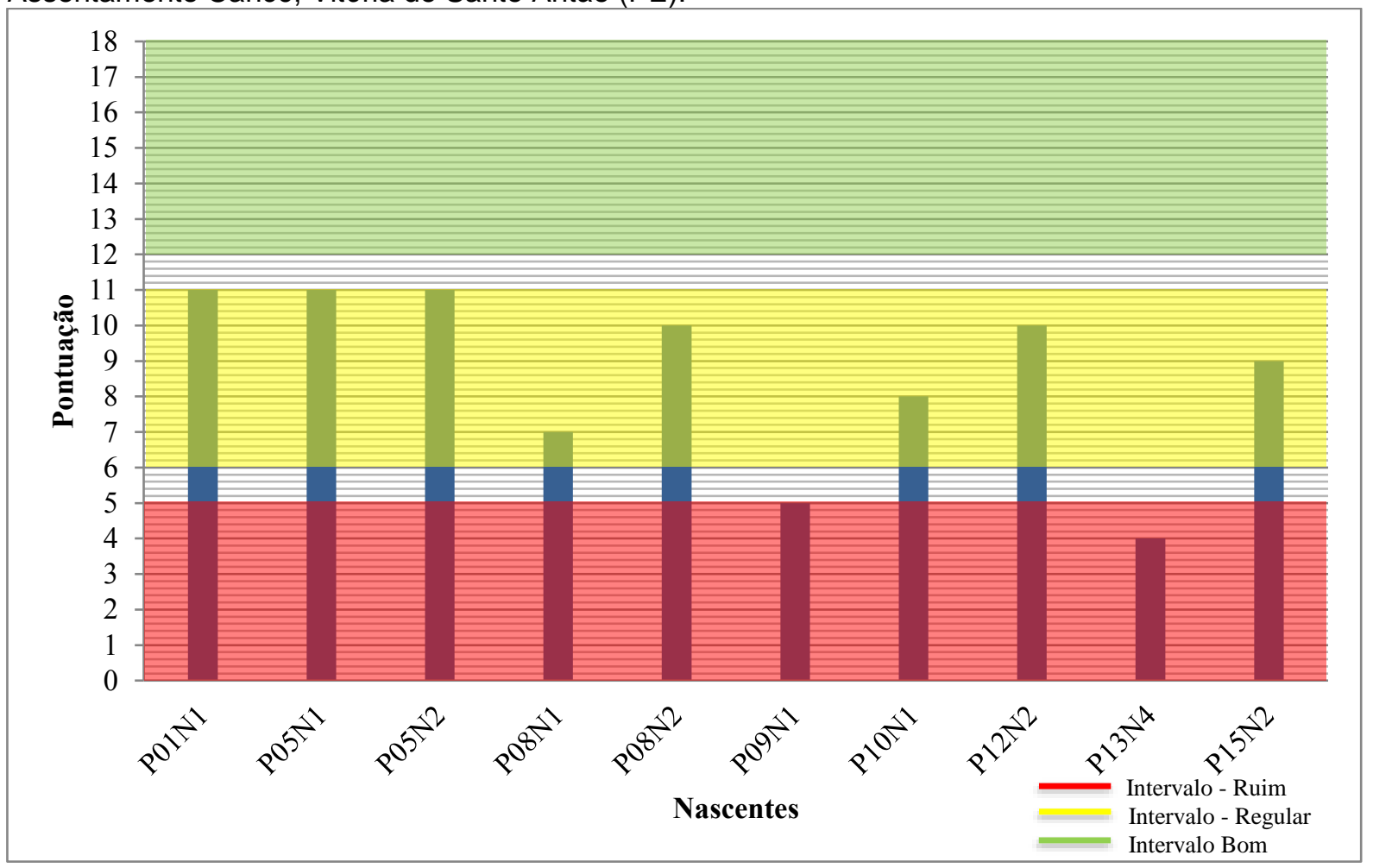

Fonte: Dados da Pesquisa de campo, em janeiro de 2013.

Pereira (2012), ao analisar 20 nascentes na Bacia do Rio Natuba - PE encontrou 13 nascentes com bom estado de conservação no corpo da nascente e 07 nos intervalos de 6 a 11, enquadradas com regular estado de conservação. Ressalta-se que a ausência de nascentes em ruim estado de conservação pode 
estar relacionada às intervenções realizadas pelo Projeto Natuba na área de estudo, com ações de conservação e melhorias das nascentes.

Com relação aos parâmetros analisados no entorno das nascentes, em específico a predominância de cobertura vegetal, observa-se a ocorrência de 14 nascentes com a presença de pasto ou agricultura de ciclo longo, restando apenas 02 nascentes, a P15N3 e P23N1 com a presença de vegetação arbustiva.

Os processos erosivos observados no solo próximos às nascentes estiveram proporcionalmente relacionados com vegetação presente no entorno. Desta forma, 14 nascentes apresentaram poucas evidências de processos erosivos no solo, restando 02 nascentes que se enquadraram ausentes devido a não indicação de evidências deste processo.

Ribeiro (2014) analisou 06 nascentes no Alto trecho da Bacia Hidrográfica do Pajeú (PE) e encontrou 03 nascentes totalmente expostas, apresentando processos erosivos; 02 nascentes com cobertura vegetal e poucas evidências de processos erosivos; e 01 nascente com pouca cobertura vegetal e a presença de rachaduras e voçorocas. Os dados da pesquisa do autor justificam a ausência de processos erosivos nesta pesquisa.

De acordo com o parâmetro uso de agrotóxicos no entorno das nascentes, 12 foram avaliadas com o pequeno índice devido ao uso esporádico destas substâncias. As nascentes P05N1, P05N2, P08N1 e P08N2 foram enquadradas devido ao uso frequente de agrotóxicos nas plantações cultivadas próximas as nascentes, com isso receberam a pontuação 01 (Figura 9).

Machado e Selva (2018) encontraram no parâmetro "Uso de Agrotóxicos nas culturas" que a maioria das nascentes (N09, N10, N12A, N12B, N18, N19 e N21) estava ausente do uso de agrotóxicos nas culturas plantadas, restando as nascentes (N05, N08, N23) a utilização de agrotóxicos em pequena dosagem, com apenas uma aplicação nas culturas plantadas na área delimitada da nascente. Usualmente aplica-se nas culturas o Roundup®.

Com relação à presença de animais de criação no entorno, observou-se que a P10N1 possuía a presença frequente destes em áreas próximas as nascentes, estando enquadrada com a pontuação 01. A P12N1, P12N2, P13N4, P15N2 e $\mathrm{P} 18 \mathrm{~N} 1$ foram as nascentes que tiveram poucas evidências de animais na área. Desta forma, 10 nascentes foram identificadas sem a presença destes (Ausente).

Ciência e Sustentabilidade - CeS / Juazeiro do Norte, v. 4, n. 1, p. 133-155, jan/jun - 2018 
Figura 9 - Estado de conservação localizado no entorno das nascentes de uso pessoal no Assentamento Caricé, Vitória de Santo Antão (PE).

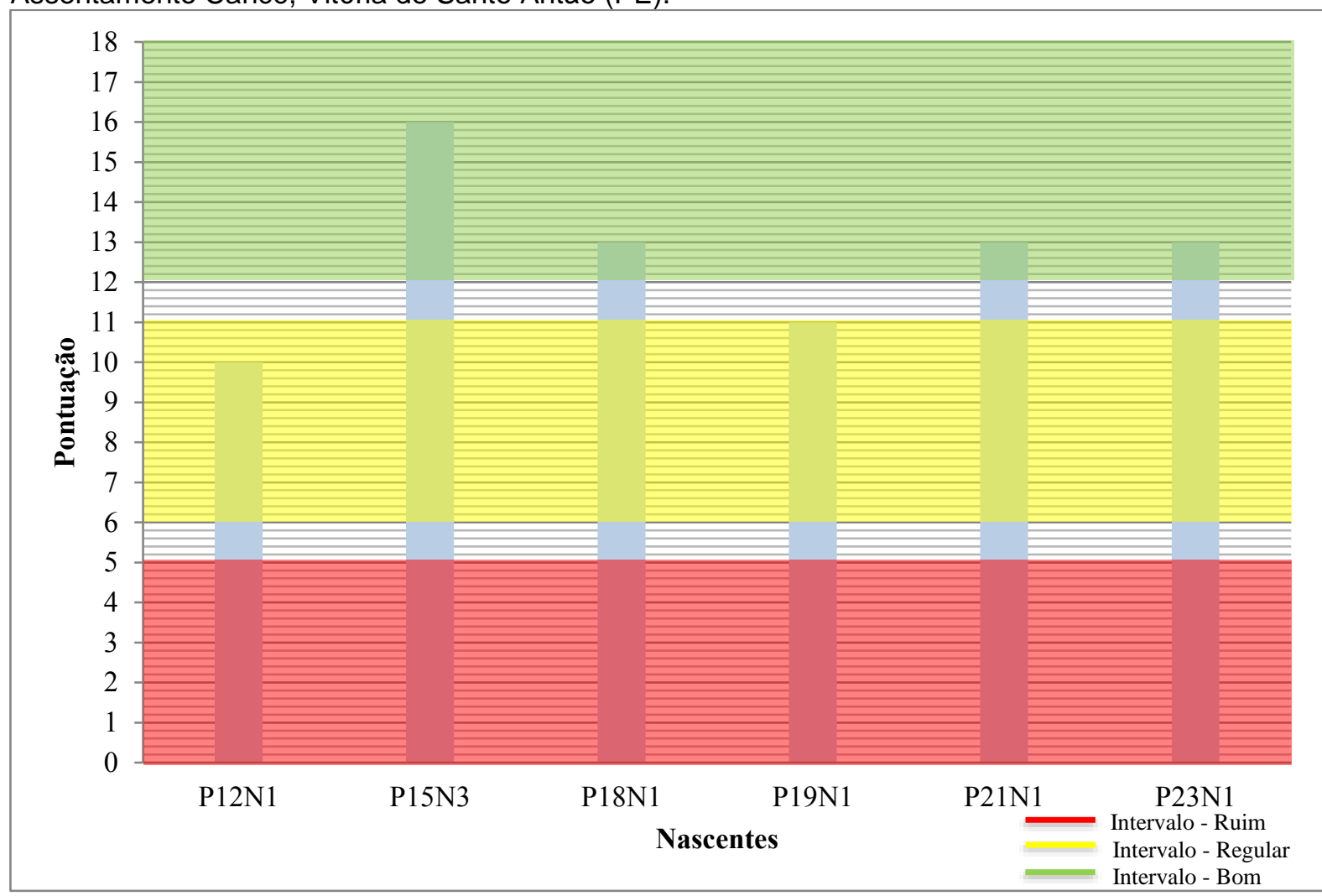

Fonte: Dados da Pesquisa de campo, em janeiro de 2013.

Machado e Selva (2018) encontraram no parâmetro "Presença de Animais de criação", que a 08 das nascentes analisadas, apresentaram o valor de 02 pontos, indicando na pesquisa poucas evidências de animais de criação na área delimitada da nascente na mesma área de estudo, de forma a não comprometer a qualidade da água da nascente.

Foram avaliadas as evidências de corte e queimadas da vegetação, neste aspecto as nascentes $\mathrm{P} 15 \mathrm{~N} 3$ e P18N1 não apresentaram vestígios desta prática. Apresentaram poucas evidências 09 nascentes, que foram identificadas com 02 pontos. Ressalta-se que 03 fontes foram enquadradas com 01 ponto, pois apresentaram evidências de utilização desta prática de forma esporádica. Desta forma, a P12N1 e a P19N1, apresentaram fortes indícios de realização de queima e/ou corte frequentes sendo atribuída a pontuação mínima.

Ciência e Sustentabilidade - CeS / Juazeiro do Norte, v. 4, n. 1, p. 133-155, jan/jun - 2018 
Oliveira (2014) analisou 17 nascentes no Assentamento Serra Grande em Vitória de Santo Antão, no Estado de Pernambuco, e encontrou 06 nascentes com o valor de 03 pontos; 06 nascentes com o valor de 02 pontos e 05 nascentes com 05 pontos. No seu estudo, os dados apontam para a prática de queimadas e/ou supressão da vegetação com os principais fatores que contribuem para degradação das nascentes, corroborando com os dados desta paesquisa.

De acordo com as observações realizadas constata-se que paras as nascentes de uso pessoal, duas encontram-se com a classificação regular (P12N1 e $\mathrm{P} 19 \mathrm{N1}$ ). As demais nascentes foram enquadradas no intervalo de 12 a 18 , consideradas com um bom estado de conservação no entorno (Figura 10).

Figura 10 - Estado de conservação localizado no entorno das nascentes de uso doméstico no Assentamento Caricé, Vitória de Santo Antão (PE).

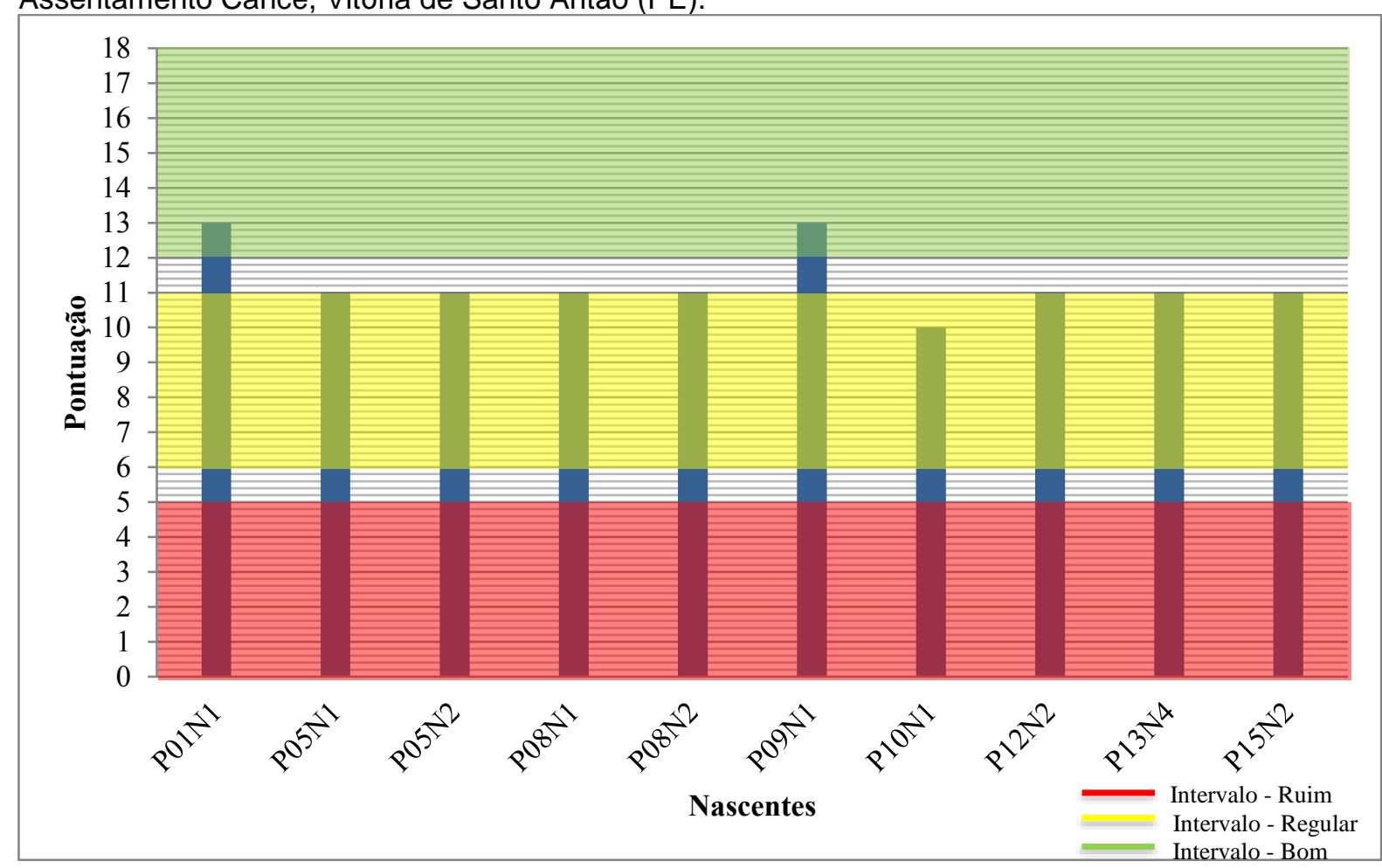

Fonte: Dados da Pesquisa de campo, em janeiro de 2013.

No parâmetro ocorrência de edificações observa-se que 10 nascentes não apresentaram construções no entorno destas, restando 06 nascentes com a pequena ocorrência de edificações e/ou residências. Ressalta-se que também foram consideradas na pesquisa as estruturas construídas, como a casa de proteção da bomba d'água (P05N1 e P10N1), com um espaço para a lavagem e banho às margens da nascente (Quadro 1).

Ciência e Sustentabilidade - CeS / Juazeiro do Norte, v. 4, n. 1, p. 133-155, jan/jun - 2018 
Quadro 1 - Estado de conservação das nascentes do Assentamento Caricé, no município de Vitória de Santo Antão, Pernambuco.

\begin{tabular}{|c|c|c|c|}
\hline NASCENTE & $\begin{array}{c}\text { ESTADO DE } \\
\text { CONSERVAÇÃOO }\end{array}$ & $\begin{array}{c}\text { USO DA } \\
\text { NASCENTE }\end{array}$ & $\begin{array}{l}\text { SITUAÇÃO } \\
\text { LOCACIONAL }\end{array}$ \\
\hline $\begin{array}{l}\text { P12N1 } \\
\text { P15N33 }\end{array}$ & $\begin{array}{l}\text { Bom } \\
\text { Bom }\end{array}$ & $\begin{array}{l}\text { Pessoal } \\
\text { Pessoal }\end{array}$ & $\begin{array}{l}\text { Corpo } \\
\text { Corpo }\end{array}$ \\
\hline P18N1 & Bom & Pessoal & Corpo \\
\hline $\mathrm{P} 19 \mathrm{~N} 1$ & Bom & Pessoal & Corpo \\
\hline P21N1 & Bom & Pessoal & Corpo \\
\hline P23N1 & Regular & Pessoal & Corpo \\
\hline P01N1 & Regular & Doméstico & Corpo \\
\hline P05N1 & Regular & Doméstico & Corpo \\
\hline P05N2 & Regular & Doméstico & Corpo \\
\hline P08N1 & Regular & Doméstico & Corpo \\
\hline P08N2 & Regular & Doméstico & Corpo \\
\hline P09N1 & Regular & Doméstico & Corpo \\
\hline P10N1 & Regular & Doméstico & Corpo \\
\hline P12N2 & Regular & Doméstico & Corpo \\
\hline P13N4 & Ruim & Doméstico & Corpo \\
\hline P15N2 & Regular & Doméstico & Corpo \\
\hline $\mathrm{P} 12 \mathrm{~N} 1$ & Regular & Pessoal & Entorno \\
\hline P15N3 & Bom & Pessoal & Entorno \\
\hline $\mathrm{P} 18 \mathrm{~N} 1$ & Bom & Pessoal & Entorno \\
\hline P19N1 & Regular & Pessoal & Entorno \\
\hline P21N1 & Bom & Pessoal & Entorno \\
\hline P23N1 & Bom & Pessoal & Entorno \\
\hline P01N1 & Bom & Doméstico & Entorno \\
\hline P05N1 & Regular & Doméstico & Entorno \\
\hline P05N2 & Regular & Doméstico & Entorno \\
\hline P08N1 & Regular & Doméstico & Entorno \\
\hline P08N2 & Regular & Doméstico & Entorno \\
\hline P09N1 & Bom & Doméstico & Entorno \\
\hline P10N1 & Regular & Doméstico & Entorno \\
\hline P12N2 & Regular & Doméstico & Entorno \\
\hline P13N4 & Regular & Doméstico & Entorno \\
\hline $\mathrm{P} 15 \mathrm{~N} 2$ & Regular & Doméstico & Entorno \\
\hline
\end{tabular}

Fonte: Dados da Pesquisa de campo, em janeiro de 2013.

Nas nascentes utilizadas para o abastecimento doméstico às observações realizadas apontam que 08 fontes apresentam a classificação regular e 02 foram enquadradas com um bom estado de conservação no entorno. Em suma, o levantamento demonstra que das 16 nascentes analisadas, 10 estão regulares quanto ao estado de conservação do entorno e 06 estão em boas condições de conservação. 


\section{CONSIDERAÇÕES FINAIS}

As análises laboratoriais realizadas constataram que a maioria das nascentes utilizadas para os usos pessoal e doméstico dentro do assentamento encontram-se em conformidade nos parâmetros de turbidez, apesar da maioria apresentar contaminação por E. coli. O que aponta estas fontes como comprometidas, principalmente para a dessedentação humana entre outras atividades substanciais que permitem a sustentabilidade no assentamento rural.

Ressalta-se nesta pesquisa a necessidade de ações de educação ambiental e sanitária, bem como a para intervenção com obras de proteção que reduzam os riscos de contaminação destas nascentes, visto que é a principal fonte hídrica que contribui para as atividades dos assentados de reforma agrária.

Ainda sobre este aspecto, recomenda-se a ampliação do estudo a partir realização de um monitoramento da qualidade da água das nascentes, nos períodos secos e chuvosos, principalmente com foco na contaminação por agrotóxicos, uma vez que algumas suspeitas foram comprovadas junto aos agricultores que utilizam esta prática nas culturas plantadas.

A identificação da situação atual de conservação das nascentes aponta que a maioria apresenta situação regular de conservação, o que evidencia a necessidade de medidas de proteção destes mananciais, que são enquadrados na legislação como áreas de preservação permanente e, no entanto, sofrem impactos diretos. Sugere-se também o desenvolvimento de ações de educação ambiental, na tentativa de estimular a reflexão destes atores sobre os impactos negativos observados nas áreas das nascentes estudadas, principalmente na importância de se conservar esses mananciais para que consequentemente eles não sejam degradados.

\section{REFERÊNCIAS}

BRAGA, R. A. P. As Nascentes como Fonte de Abastecimento de Populações Rurais Difusas. Revista Brasileira de Geografia Física. Recife. Dez. 2011. Disponível em:

<http://www.revista.ufpe.br/rbgfe/index.php/revista/article/view/265/222>. Acesso em: 07 mai. 2016.

Ciência e Sustentabilidade - CeS / Juazeiro do Norte, v. 4, n. 1, p. 133-155, jan/jun - 2018 
BRASIL. Lei no 12.651, de 25 de maio de 2012. Disponível em: < http://www.planalto.gov.br/ccivil_03/_ato2011-2014/2012/lei//12651.htm>. Acesso em: 10 jun. 2016.

CHRISTODIFIS, D. Considerações sobre conflitos e uso sustentável em recursos hídricos. In: THEODORO, S. H. (Org.). Conflitos e uso sustentável dos recursos naturais. Rio de Janeiro: Garamond, 2002.

CONAMA - Conselho Nacional de Meio Ambiente. Resolução no 303, de 20 de março de 2002. Dispõe sobre parâmetros, definições e limites de Áreas de Preservação Permanente. Disponível em: < http://www.mma.gov.br/port/conama/legiabre.cfm?codlegi=299>. Acesso em: 03 set. 2016.

Resolução no 357, de 17 de março de 2005. Dispõe sobre a classificação dos corpos d'água e diretrizes ambientais para o seu encaminhamento, bem como estabelece padrões de lançamento de efluentes. Disponível em: <http://www.mma.gov.br/port/conama/res/res05/res35705.pdf>. Acesso em: 03 set. 2016.

.Resolução $\mathrm{n}^{\circ}$ 274, de 29 de Novembro de 2000. Dispõe sobre as condições de balneabilidade. Disponivel em: <http://www.mma.gov.br/port/conama/res/res00/res27400.html>. Acesso em: 03 set. 2016.

CPRM. Serviço Geológico do Brasil. Projeto cadastro de fontes de abastecimento por água subterrânea. Diagnóstico do Município de Vitória de Santo Antão, estado de Pernambuco. Recife: CPRM/PRODEEM, 2005. Disponível em: <http://www.cprm.gov.br/rehi/atlas/pernambuco/relatorios/VDSA173.pdf>. Acesso em: 12 nov. 2012.

Carta de Suscetibilidade a Movimentos Gravitacionais de Massa e Inundação. Município de Vitória de Santo Antão - PE. Brasília, 2014.

CUNHA, F. A. G. C. da. Unidades de conservação como fornecedoras de serviços ambientais. 2014. 183 f. Dissertação (Mestrado em Desenvolvimento e Meio Ambiente) - Universidade Federal de Pernambuco, Recife. 2014.

DAVIS, et al. Springs: Conserving perennial water is critical in arid landscapes. Biological Conservation. 2017. Disponível em: < http://dx.doi.org/10.1016/j.biocon.2016.12.036>. Acesso em: 26 set. 2017.

FELIPPE, M. F., MAGALHÃES JUNIOR, A. P. Conflitos conceituais sobre nascentes de cursos d'água e propostas de especialistas. Geografias. Belo Horizonte. Jan./Jun. 2013. Disponível em:

<http://www.igc.ufmg.br/portaldeperiodicos/index.php/geografias/article/view/583/453 >. Acesso em: 07 jan. 2017.

. Impactos ambientais macroscópicos e qualidade das águas em nascentes de parques municipais em Belo Horizonte - MG. Geografias. Belo Horizonte jul/dez. 2012. Disponível em: < 
http://www.igc.ufmg.br/portaldeperiodicos/index.php/geografias/article/view/568/438> . Acesso em: 29 set. 2017.

GUSMÃO, P. T. R. et al. Qualidade da água em nascentes do Rio Natuba - PE. In: Simpósio

Brasileiro de Recursos Hídricos, XIX. 2011, Maceió. Anais... Maceió: ABRH, 2011.

IBGE. Instituto Brasileiro de Geografia e Estatística. Malhas digitais. 2010.

Disponível em: < https://mapas.ibge.gov.br/bases-e-referenciais/bases-

cartograficas/malhas-digitais.html>. Acesso em: 29 set. 2016.

INCRA - Instituto Nacional de Colonização e Reforma Agrária. Plano de Desenvolvimento do Assentamento Caricé. Executor Técnico: Empresa de Abastecimento e Extensão Rural de Pernambuco. Convênio INCRA/EBAPE. Vitória de Santo Antão - PE, 2002.

\section{MACHADO, L. C. O Papel das Nascentes na Sustentabilidade de}

Assentamentos Rurais. 2013. 126f. Dissertação (Mestrado em Desenvolvimento e Meio Ambiente) - Universidade Federal de Pernambuco, Recife. 2013.

MACHADO, L. C.; SELVA, V. S. F. Avaliação do Potencial de Conservação de Nascentes na Zona da Mata Pernambucana. Revista Geama. Recife. v. 4. n. 1. Jan./Mar. 2018. Disponível em: <

http://www.journals.ufrpe.br/index.php/geama/article/view/1661/1568>. Acesso: 28 fev. 2018.

MACHADO, L. C.; SOARES, D. B. Caracterização de Nascentes da Bacia Hidrográfica do Rio Capibaribe em Assentamento Rural. Revista Geama. Recife. v. 4. n. 2. Abr./Jun. 2018. Disponível em: < http://www.journals.ufrpe.br/index.php/geama/article/view/1832>. Acesso: 12 jun. 2018.

MS. Ministério da Saúde. Portaria ${ }^{\circ}$ 2914: procedimentos de controle e de vigilância da qualidade da água para consumo humano e seu padrão de potabilidade. Brasília. 2011.

OLIVEIRA, C. R. de. Qualidade da água e conservação de nascentes em assentamento rural na mata pernambucana. 2014. $141 \mathrm{f}$. Dissertação (Mestrado em Engenharia Civil) - Universidade Federal de Pernambuco, Recife. 2014.

OLIVEIRA, D.G. et al. Análise da vegetação em nascentes da Bacia Hidrográfica do Rio Piauitinga, Salgado, SE. Revista Árvore. Viçosa-MG. v. 36. 2012. Disponível em: < http://www.scielo.br/pdf/rarv/v36n1/a14v36n1.pdf>. Acesso: 02 out. 2017.

PEREIRA, L. C. Uso e conservação de nascentes em assentamentos rurais. 2012. 166 f. Dissertação (Mestrado em Engenharia Civil) - Universidade Federal de Pernambuco, Recife. 2012. 
PERNAMBUCO. Atlas de bacias hidrográficas de Pernambuco. Recife:

Secretaria de Ciência, Tecnologia e Meio Ambiente, 2006.

PINTO, L. V. A. Caracterização física da sub-bacia do Ribeirão Santa Cruz, Lavras, MG, e proposta de recuperação de suas nascentes. 2003. $165 \mathrm{f}$.

Dissertação (Mestrado em Engenharia Florestal) - Universidade Federal de Lavras, Minas Gerais. 2003.

PINTO, L. V. A., et al. Avaliação qualitativa da água de nascentes com diferentes usos dos solos em seu entorno. Cerne. v. 18. jul./set. 2012. Lavras - MG. Disponível em: < http://www.scielo.br/pdf/cerne/v18n3/a18v18n3.pdf >. Acesso em: 02 out. 2017.

REBOUÇAS, A. C. Água doce no mundo e no Brasil. In: REBOUÇAS, A. C.; BRAGA, B.; TUNDISI, J. G. Águas doces no Brasil: capital ecológico, uso e conservação. 3. ed. São Paulo: Escrituras Editora, 2006.

RIBEIRO, A. S. Estado de conservação das nascentes do alto trecho do Rio Pajeú, Pernambuco, Brasil. 2014. 202 f. Dissertação (Mestrado em Desenvolvimento e Meio Ambiente) - Universidade Federal de Pernambuco, Recife. 2014. 